\title{
A PROPOSAL TO IMPLEMENT INTEGRATED GIS SYSTEM IN DISSEMINATING SPATIAL INFORMATION FOR MALAYSIA DEVELOPMENT APPROVAL (STAKEHOLDERS AND APPLICANTS) - A CONCEPT PAPER
}

\author{
Hairi Karim ${ }^{1}$, Dato Abdul Latif Abu Seman ${ }^{2}$, Mohamad Azrol Mohamad Dali ${ }^{2}$, Siti Zurianah Othman ${ }^{2}$, and Siew Chengxi Bernad ${ }^{3}$ \\ ${ }^{1}$ I Net Spatial Sdn Bhd, \\ Taman Pulai Utama, 81300 Skudai, Johor, Malaysia. \\ wmhairi@inetspatial.com \\ ${ }^{2}$ Malaysia Productivity Corporation (MPC), \\ Peti Surat 64, Jalan Sultan, \\ 46904 Petaling Jaya, Selangor, Malaysia. \\ mdazrol@mpc.gov.my and zurianah@mpc.gov.my \\ ${ }^{3}$ Geotech Solutions Sdn Bhd \\ 27, Jalan 7/40, Taman Pusat Kepong, 52000, Kuala Lumpur \\ bernad@bernadsiew.com
}

KEY WORDS: Development approval, GIS collaborative solution, stakeholders and users, cost-time-procedure, Geomap solution.

\begin{abstract}
Every year, World Bank Group (WBG) is conducting assessment for 190 countries and produces a ranking report based on Doing Business performance - an initiative to measure benchmark efficiency on business regulation and their enforcement by a sample study (e.g. for Malaysia is Kuala Lumpur City Hall - DBKL). One of the ranking categories is based on Dealing with Construction Permits (DCP) which made us proud as announce Malaysia ranks for 2019 is \#3 (based on 2018 assessment). This achievement was based on continues efforts and studies from the last bottom of \#137 (since, 2007), \#113 (2012) and continues with positive results (straight improvement) respectively till this year. Maintaining the top three ranks is not an easy task; however, is not impossible either. Lots of study in innovations, suggestions and implementation should be carried out to maintain and improve Malaysian DCP ranks. As per DCP of this year assessment, Work Bank has suggested all countries with 5 new suggestions (new additional marking schema). One of them is to engage Geographic Information System (GIS) for land use, cadastre, water, electricity and sewage related datasets. This paper propose an initial study (concept paper) towards engaging GIS in DCP activity as a response (first action) suggested by World Bank Group; crucial in maintaining DCP rank for 2020 as well as to provide better business regulations and enforcements for DBKL or other local authority. Later, an impact study will be conducted, utilizing new integrated GIS system publishing service (GeoMap) and the output of the study will indicate whether Malaysia Productive Corporation (MPC) should engage or ignore the $5^{\text {th }}$ suggestion by World Bank Group, or to enhance with other initiatives.
\end{abstract}

\section{INTRODUCTION}

Since 2002, a yearly list of country ranks will be given by World Bank group (WBG) to indicate a comparative and statistical report on business regulation for domestic firms (small and medium companies). The rank and marks are different based on 11 groups of categories starting from a business regulation, dealing with construction permits (DCP), getting electricity, up to labour market regulations. The objective of this Doing Business project is to measure business regulations and their enforcement across 190 economies and selected cities at the subnational and regional level.

The ranking report is an initiative to measure benchmark efficiency on business regulation and their enforcement by a sample study (e.g. for Malaysia is Kuala Lumpur City Hall DBKL). For 2018 DCP ranking (based on 2018 assessments), Malaysia is ranked as number 3 out of 190 countries. This achievement was based on continues efforts and studies from the last bottom of \#137 (since, 2007), \#113 (2012) and continues with positive results (straight improvement) respectively till now. Maintaining the top three ranks is not an easy task; however, is not impossible either. Lot of study in innovations, suggestions and implementation should be carried out to maintain or improve our DCP ranks. Different parameters are used for each category in scoring processes; e.g. DCP - procedures, time and cost to complete all formalities to build a warehouse and the quality control and safety mechanisms in the construction permitting system (WBG, 2019). As per DCP of this year assessment, WBG has suggested all countries with 5 new suggestions (new additional marking schema). One of them is to engage with Geographic Information System (GIS) for land use, cadastre, water, electricity and sewage related datasets. GIS technology hopefully gives significant impact on minimizing procedure of acquiring preliminary geospatial data and reduce the cost with a good quality index performance.

GIS is a term refers to a digital system designed to capture, store, manipulate, analyse, manage, present and disseminate spatial or geographic data (Cantwell and Milem, 2010) for public or decision makers. The system utilises spatial data and attributes (related tabular information/characteristic of its spatial data) for decision making process of particular the area for example for development, environment protection, security, businesses development, taxation, and other inventory tasks. 


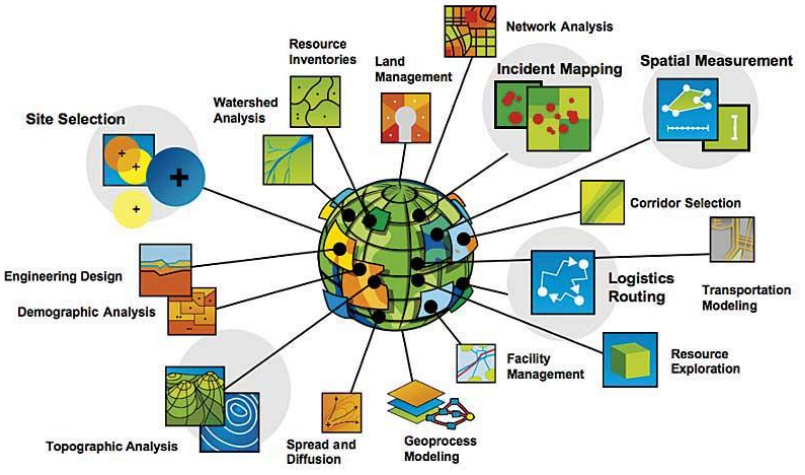

Figure 1: Applied GIS around the world across disciplines, professions and organizations (ESRI, 2007).

Most of the authorities either in local, state, federal / national, regional or international (global) levels have fully utilize GIS in order to have better understanding, information, control and good planning for their respective jurisdiction area (as illustrated in Figure 2). Each and every authority may have the same spatial database standard (for data viewing and retrieval), but normally having different purpose (specific task) or for respective application/system as their operation is concerned (e.g. approval for construction permit).

In general, Malaysian administrative system is divided into three major levels; Federal Government, State Government and Local Government. The planning powers of local authorities (Local Government Act 1976 (Act 171)) were stipulated in the allied Town and Country Planning Act (Yaakup et al., 1998). The act stated that the local authority shall be the local planning authority for the area of the local authority (a right to grant or refuse any planning application as well as to monitor the progress quality). Thus, local authority shall engage and collaborate with other stakeholders such as utility providers (water, electricity, gas etc), infrastructures (e.g. $\mathrm{road} /$ transportation, drainage), and the development applicants (e.g. developer) for any development application request.

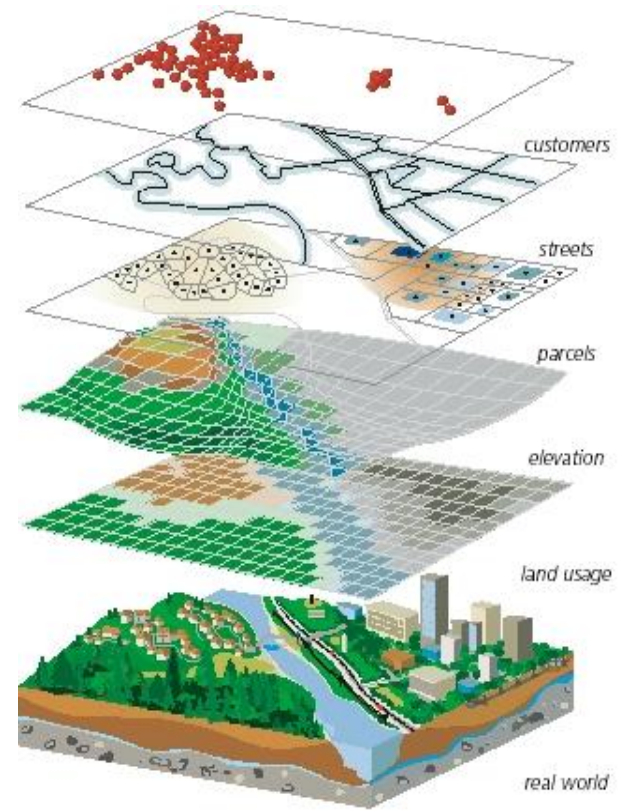

Figure 2: GIS spatial modelling for better management especially for authorized body.

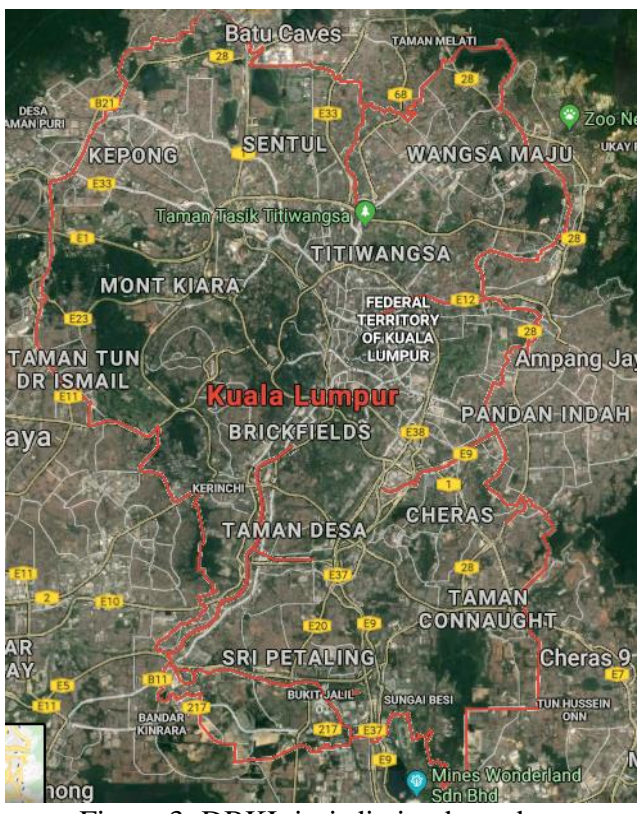

Figure 3: DBKL jurisdiction boundary

\section{BACKGROUND OF THE STUDY}

This section discusses brief summary on current implementation approaches. Previously before 2007 (One Stop Centre - OSC was fully implemented in all local authorities on June 2007), local authority has their own set of procedures in dealing and controlling construction approval permit. For example, DBKL uses its own set of procedures assisted with GIS in Figure 4. As for current practice, all local authorities have engaged with OSC model (will be discussed in section 2.1) for their development approval process.

\begin{tabular}{|c|c|c|}
\hline Stages & Activities & Function of GIS \\
\hline Initial Discussion & $\begin{array}{l}\text { Consultation to owner/ } \\
\text { developer regarding potential, } \\
\text { planning requirement, policies } \\
\text { involved in the area }\end{array}$ & $\begin{array}{l}\text { Data Retrieval: } \\
\text { a) Existing development } \\
\text { b) Development status } \\
\text { c) Development Plan } \\
\text { d) Planning policies }\end{array}$ \\
\hline $\begin{array}{l}\text { Processing of Planning } \\
\text { Application }\end{array}$ & $\begin{array}{l}\text { - registration } \\
\text { - site visit } \\
\text { - gathering data from various } \\
\text { departments } \\
\text { - identifying planning issues } \\
\text { - preparing technical report } \\
\text { - analyzing the application }\end{array}$ & $\begin{array}{l}\text { - identify potential land for } \\
\text { development } \\
\text { - translate policies formulated into } \\
\text { spatial context } \\
\text { - identify development pressure } \\
\text { area }\end{array}$ \\
\hline $\begin{array}{l}\text { Consideration by } \\
\text { Technical Sub } \\
\text { Committee }\end{array}$ & $\begin{array}{l}\text { - comment on technical } \\
\text { requirement } \\
\text { - recommend the technical } \\
\text { amendment to applicant }\end{array}$ & $\begin{array}{l}\text { - data retrieval from various } \\
\text { agencies } \\
\text { - facilitate technical evaluation }\end{array}$ \\
\hline $\begin{array}{l}\text { Consideration by Town } \\
\text { Planning } \\
\text { Committee }\end{array}$ & $\begin{array}{l}\text { - formulate and review } \\
\text { planning policies } \\
\text { - considering planning } \\
\text { application }\end{array}$ & $\begin{array}{l}\text { - assist in analyzing the development } \\
\text { strategy } \\
\text { - provide information to evaluate the } \\
\text { planning implication }\end{array}$ \\
\hline
\end{tabular}

Figure 4: Example of self-procedure and GIS function at DBKL for DCP before 2007 (Foziah et al., 2006).

While for DCP scoring (DCP world ranking) by WBG, a concerned basically is given to tracks the efficiency of procedures, minimum time and cost for a new development design including obtaining necessary the licenses and permits, submitting all required notifications, requesting and receiving all necessary inspections and obtaining utility connections at the proposed area. In addition, it also measures the building quality control index, evaluating the quality of building regulations, the strength of quality control and safety mechanisms, liability and insurance regimes, and professional certification requirements. 
The International Archives of the Photogrammetry, Remote Sensing and Spatial Information Sciences, Volume XLII-4/W16, 2019 6th International Conference on Geomatics and Geospatial Technology (GGT 2019), 1-3 October 2019, Kuala Lumpur, Malaysia

Some indications/scores to be measured by WBG are but not limited to:

1. Procedures to legally build a warehouse/building (number)

a. Submitting all relevant documents and obtaining all necessary clearances, licenses, permits and certificates.

b.Submitting all required notifications and receiving all necessary inspections

c. Obtaining utility connections for water and sewerage

d.Registering and selling the warehouse/building after its completion

2. Time required to complete each procedure (calendar days):

a. Does not include time spent gathering information

b.Each procedure starts on a separate day - though procedures that can be fully completed online are an exception to this rule c. Procedure is considered completed once final document is received

d.No prior contact with officials

3. Cost required to complete each procedure (\% of income per capita):

a. Official costs only, no bribes

b.Building quality control index (0-15)

c. Quality of building regulations (0-2)

d.Quality control before construction (0-1)

e. Quality control during construction (0-3)

f. Quality control after construction (0-3)

g.Liability and insurance regimes (0-2)

h.Professional certifications (0-4)

\begin{tabular}{|c|c|c|c|c|}
\hline \multicolumn{2}{|l|}{ Estimated value of warehouse } & \multicolumn{3}{|c|}{ MYR $2,082,058.10$} \\
\hline City Covered & & Jala Lumpur & & \\
\hline Indicator & Malaysia & $\begin{array}{l}\text { East Asia \& } \\
\text { Pacific }\end{array}$ & $\begin{array}{l}\text { OECD high } \\
\text { income }\end{array}$ & $\begin{array}{l}\text { Best Regulatory } \\
\text { Performance }\end{array}$ \\
\hline Time (days) & 54 & 133.5 & 153.1 & None in $2017 / 18$ \\
\hline Cost ( $\%$ of warehouse value) & 1.4 & 1.9 & 1.5 & None in $2017 / 18$ \\
\hline Building quality control index $(0-15)$ & 13.0 & 9.1 & 11.5 & 15.0 (3 Economies) \\
\hline
\end{tabular}

DB 2019 Dealing with Construction Permits Score

$\mathbf{0}$

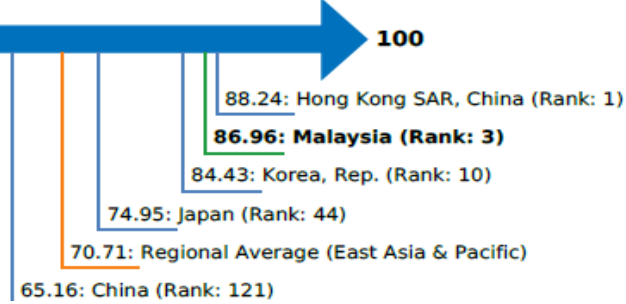

Figure 5: 2018 DCP ranking score for Malaysia and other highlighted countries.

Note: The ranking of economies on the ease of dealing with construction permits is determined by sorting their scores for dealing with construction permits. These scores are average scores.

\subsection{Current Procedures}

New Model of OSC 3.0

Start

\begin{tabular}{|c|c|c|c|c|c|}
\multicolumn{2}{|c}{$\mathbf{P 1}$} & $\mathbf{P 2}$ & $\mathbf{P}$ & \multicolumn{2}{c|}{ P4 } \\
\hline $\begin{array}{c}\text { Pre- } \\
\text { negotiations }\end{array}$ & $\begin{array}{c}\text { Approval of } \\
\text { proposed design }\end{array}$ & $\begin{array}{c}\text { Notice to start the } \\
\text { construction work }\end{array}$ & $\begin{array}{c}\text { Interim } \\
\text { Inspection }\end{array}$ & $\begin{array}{c}\text { Inspection 1 } \\
\text { \& II (final) }\end{array}$ & $\begin{array}{c}\text { CCC deposit } \\
\text { and Form G }\end{array}$ \\
\hline Process 1 & Process 2 & Process 3 & Process 4 & Process 5 & Process 6 \\
\hline
\end{tabular}

Figure 6: New OSC model (3.0) for planning approval. 
The International Archives of the Photogrammetry, Remote Sensing and Spatial Information Sciences, Volume XLII-4/W16, 2019 6th International Conference on Geomatics and Geospatial Technology (GGT 2019), 1-3 October 2019, Kuala Lumpur, Malaysia

Table 1: Number of procedures, involvement from related agencies, and time/cost involve for a development project at RM2 million.

\begin{tabular}{|l|l|c|c|c|}
\hline No & Procedure & Agency & Days & Charge \\
\hline 1 & $\begin{array}{l}\text { Obtain technical conditions from the Water Authority } \\
\text { SYABAS }\end{array}$ & SYABAS & 2 days & no charge \\
\hline 2 & Submit and obtain development approval through OSC & OSC & 30 days & RM 3,600 \\
\hline 3 & Submit pre-construction notifications to OSC & OSC & 1 day & no charge \\
\hline 4 & Request final utilities inspections through OSC & OSC & 1 day & 2,163 \\
\hline 5 & Receive road and drainage inspection & Eng. DBKL & 1 day & no charge \\
\hline 6 & Receive final inspection from water utility & SYABAS & 1 day & no charge \\
\hline 7 & Obtain sewerage connection & Fire \& Rescue & 1 days & RM 20,821 \\
\hline 8 & Receive fire safety inspection charge \\
\hline 9 & Obtain clearance letters from OSC - single window & OSC & 1 day & no charge \\
\hline 10 & $\begin{array}{l}\text { Builder's principal submitting person files certificate of } \\
\text { completion and compliance (CCC) }\end{array}$ & OSC & 1 day & no charge \\
\hline 11 & Obtain water connection & SYABAS & 3 days & RM 1,600 \\
\hline & Total : Procedure 11 & & $\mathbf{5 4}$ days & RM 28,184 \\
\hline
\end{tabular}

\section{Phase 1 (P1):}

- Pre-negotiation is COMPULSORY for MCMC, SYABAS, TNB, PTD, LPHS (residential development> 5 acres and above) and KSAS (development in Class III and above).

- Pre-negotiation reviews (LPHS review letter and letter of approval of environment Sensitive Area Committee (KSAS) it is compulsory) while the application for process may be submitted together with pre-negotiated notification letters have been made.

\section{Phase 2 (P2):}

Land matters must be completed at the Planning Permission Application stage. The land premium must be settled before submitting an Application Plan for Infrastructure and Building Plan simultaneously or separately.

- Simultaneous Application (KM $+\mathrm{INF}+\mathrm{BGN})$ is only allowed if the land deal has been resolved.

- Planning Planner provides KM compliance reviews at the Building Plan level for development that has been approved by KM. For additional applications and temporary building permits, JPP reviews are subject to certain cases only.

- Solid Waste Management and Public Cleansing Department (JPSPPA) provide comments on the Planning Permission application stage involving strata development only.

In general there are two project categories (small and medium) which fall under this procedure. These two categories also subdivided by the source of the project as follow:

- Project categories based on Ministry of Housing and Local Government

- Special OSC Category Projects

\subsection{Category of Projects}

\subsubsection{Small Scale}

Small scale projects involve concurrent applications for proposed development for residential buildings as follows:

i. Proposed addition and change to an existing house and;

ii. A new proposal for a single residential unit;

iii. Proposal to demolish and rebuild a single house. 
- PLANNING PERMISSION (Development Order)

- building PLAN

- ENGINEERING PLANS (Earthworks Plan + Roads and Drainage Plan + Street Lighting plan)

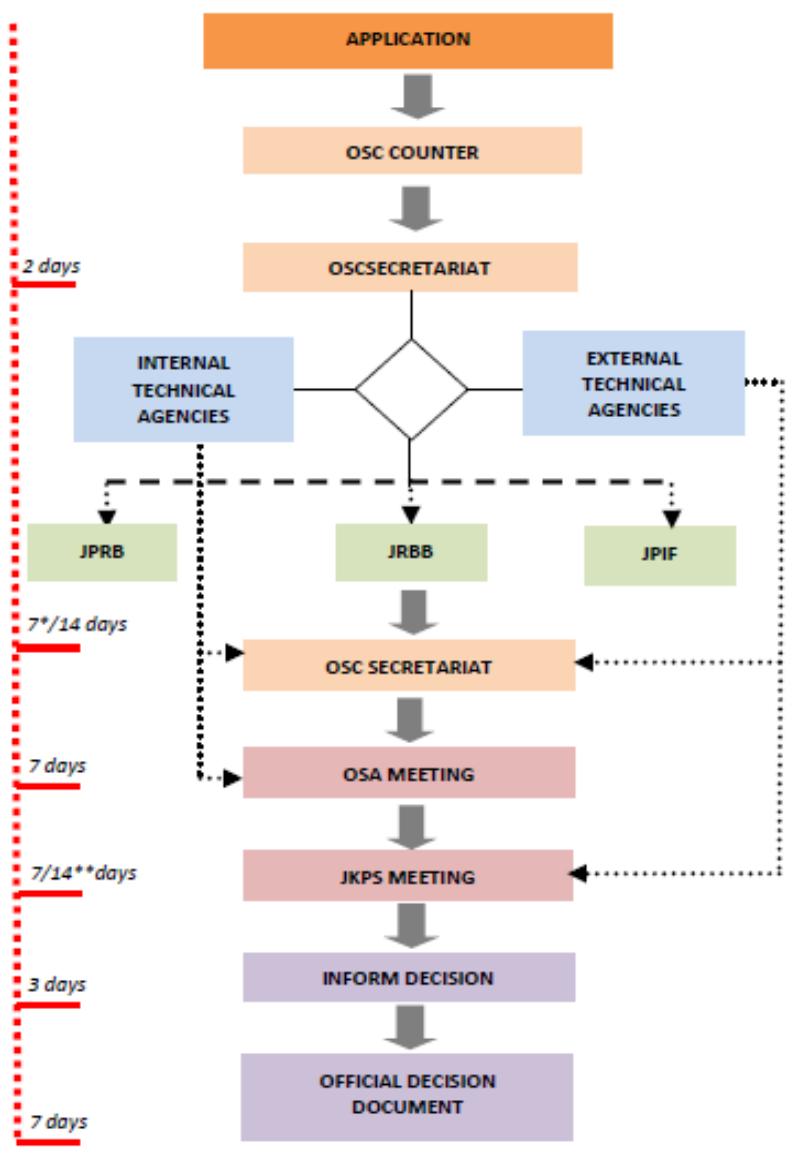

Applicant submits a complete application ( 3 simultaneous application)

OSC COUNTER

1. Receive complete application

2. Check and register application

OSC SECRETARIAT : Distribute and submit document to:

1. JPRB, JRBB and JPIF for processing

2. Internal technical departments/agencies for evaluation/ endorsement.

3. External technical agencies/ departments for evaluation/ endorsement

EXTERNAL AND INTERNAL TECHNICAL AGENCIES

Check documents and forward the written comments/ recommendation to the JPRB, JRBB and JPIF. A copy of the written comments/ recommendations to be submitted to the OSC Secretariat.

\section{JPRB, JRBB DAN JPIF}

1. Check documents and prepare a paper on the recommendations incorporating the comments from the Internal and External Technical agencies.

2. A complete recommendation paper is submitted to the OSC Secretariat

OSCSECRETARIAT

1. Receives the Document from JPRB, JRBB and JPIF.

2. Prepare Agenda for meeting

3. Fix the date, time and venue of meeting

4. Issue out invitations to the meeting

\section{MEETING}

1. Discuss application to arrive at a decision

2. Review/ endorsement of internal technical agencies will be required

JKPS MEETING

1. Discuss the application to arrive at a decision

2. Comments/ recommendations by external technical agencies (AT) are required

\section{INFORM DECISION}

A letter to be issued to the applicant to inform the decision by the processing department

OFFICIAL DOCUMENT OF DECISION

The official document confirming the decision is given to the applicant by the processing department after all requirements are complied with.

"If application is a government project

*If the special osc committee is held once in 2 weeks

TOTAL 47 DAYS

Figure 7: Small scale planning approval procedure.

\subsubsection{Medium Scale}

i. Medium scale projects involve the following applications:

ii. A proposed development that complies with an approved layout and is not in conflict with the PBRKL 2020 for the following:

- Residential house : 2 to 5 units AND not exceeding 3 storeys

- Shophouse: Not exceeding 2 lots AND not exceeding 5 storeys in height.

- A Building block (commercial, industry and institution not including religious use)

○ Not exceeding 2 storeys

- Total floorspace not exceeding 5,000 square feet

- Additions and changes involving a floorspace area not exceeding 2,000 square feet.

iii. Subdivision of land not exceeding 4 residential lots in line with the area's planning guidelines except for sensitive areas such as Bukit Tunku, Taman Duta, Bukit Damansara, Bukit Persekutuan, Bukit
Bandaraya, Sungai Penchala, areas around the National Palace and Bukit Gasing.

iv. Amalgamation of residential lots not exceeding 4 lots in line with the area's planning guidelines.

v. Change of use of a building in line with the landuse zoning (eg: shop/office into budget hotel, private college, entertainment centre or Spa centre)

vi. Temporary change of use of building not in line with the landuse zoning (such as residential to restaurant, office, children's day care centre and kindergarten)

vii. Construction of temporary buildings

viii. Construction of telecommunication towers

ix. Additional floor to an existing shophouse provided the total height does not exceed 5 storeys

x. Extension of Development Order

xi. Naming and re-naming of building or development scheme

xii. Proposal to upgrade existing building façade

xiii. Small addition or change not including free standing buildings 


\section{- PLANNING PERMISSION (Development Order) \\ - BUILDING PLAN}

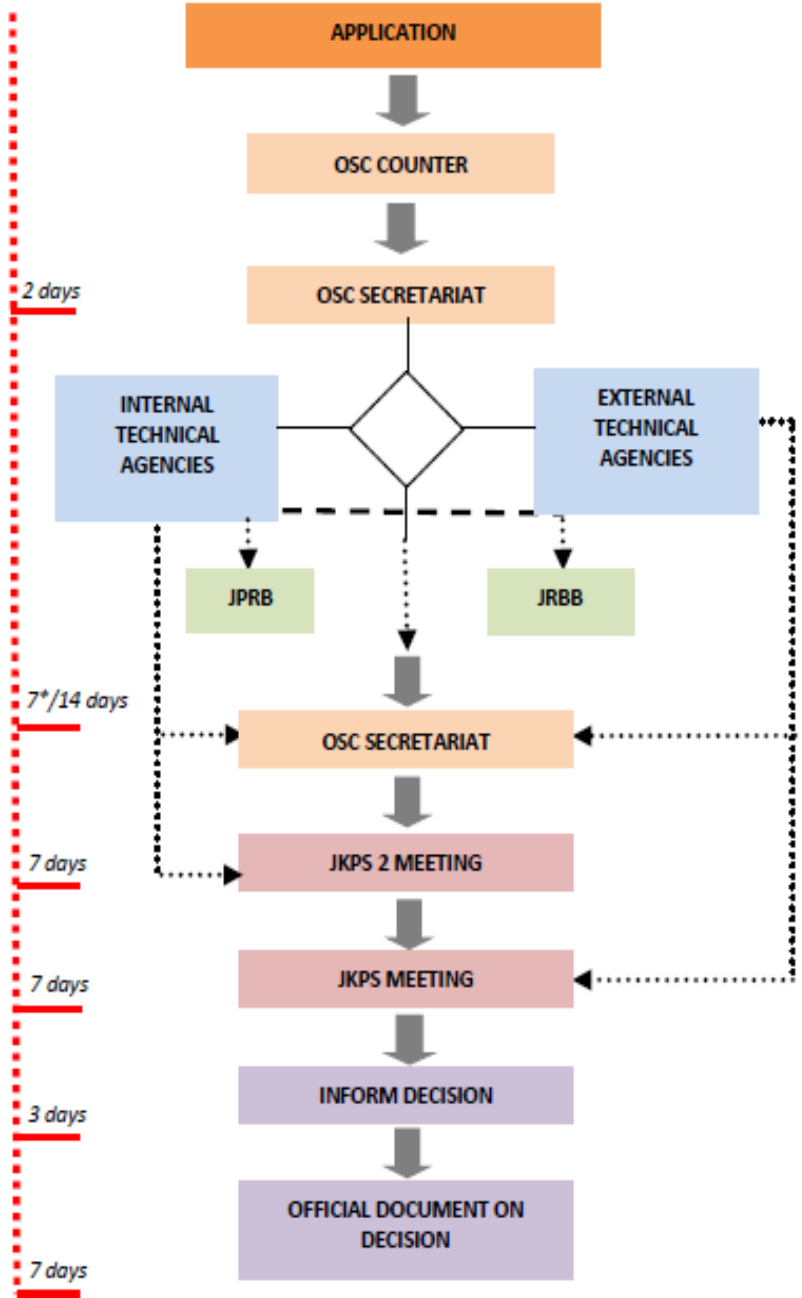

\section{Applicant submits a complete application ( 2 concurrent application)} OSC COUNTER

1. Receive complete application

2. Check and register application

OSC SECRETARIAT : Distribute and submit document to:

1. JPIF for processing

2. Internal technical departments/ agencies for evaluation/ endorsement.

3. External technical agencies/ departments for evaluation/ endors EXTERNAL AND INTERNAL TECHNICAL AGENCIES

Check documents and forwarld the written comments/ recommendation to the JPRB and JRBB. A copy of the written comments/ recommendations to be submitted to the OSC Secretariat. JPRB AND JRBB

1. Check documents and prepare endorsement paper incorporating all comments/ recommendations by external/ internal agencies.

2. The complete Endorsement Paper shall be submitted to OSC Secretariat.

\section{OSCSECRETARIAT}

1. Receives the Document from JPRB and JRBB

2. Prepare Agenda for meeting

3. Fix the date, time and venue of meeting

4. Issue out invitations to the meeting

\section{JKPS 2 MEETING}

1. Discuss application to arrive at decision

2. Review / endorsement from internal technical agencies is required.

JKPS MEETING

1. Obtain JKPS confirmation

INFORM DECISION

A letter to be issued to the applicant to inform the decision by the processing department

OFFICIAL DOCUMENT OF DECISION

The official document confirming the decision is given to the applicant by the processing department after all requirements are complied with.

* If application is a government project

TOTAL 40 DAYS

Figure 8: Medium scale planning approval procedure.

\subsection{Availability of Online Mapping Platform}

Advanced technology recent years has support complex development on mapping system / platform; especially for data sharing and security across multiple users and data sources. Various mapping related applications newly developed to emerge the platform from basic / simple approach such as utilizing single geo-database with multiple applications to the most complex systems (e.g. multiple users, data sources and payment gateway for purchasing online data).

Three current main architecture categories in GIS system implementation are; Stand-alone (working with only a machine), Enterprise (organization own GIS unit) and Integrated architecture (where users can have benefits from combined data of various stakeholders/data providers).

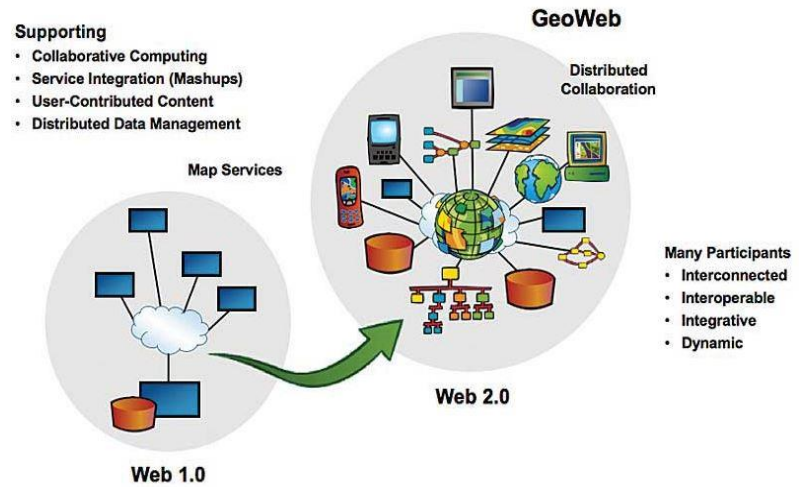

Figure 9: Example of web-map infrastructure revolution from single organization uses to collaborated system (ESRI, 2007). 


\section{THE STUDY CONCERN}

This section will be divided into three sub-section; aim/objective, target stakeholders, data/study area.

\subsection{Aim and Objectives}

The aim of this paper is to conduct and present the initial study (impact) of the 5th World Bank Group's suggestion for DCP; to link the Geographic Information System (GIS) for land use, cadastre, water, electricity and sewage dataset.

While the objectives of this concept paper are:

i. To provide working solution engaging GIS system for DCP (assist PSP/SP gather initial information and data before submitting plan.

ii. To assess impacts on facilitating preliminary data gathering using integrated GIS architecture.

iii. To assess the satisfactory and user friendly of this solution, comments among stakeholders and submitting entity (developers/agent -PSP/SP).

iv. To recommend improvement of future GIS system (requirements) and promotion strategies to attract more participating stakeholders.

\subsection{Targeted Stakeholders}

The main stakeholder involve in this study is DBKL personnel which involve directly with $\mathrm{DCP} /$ planning approval procedures $\left(1^{\text {st }}\right.$ and $2^{\text {nd }}$ phases). Other stakeholders are from infrastructure and utility providers such as:

CIDB

Jabatan Kerja Raya JKR

SYABAS Berhad (fresh water)

Indah Water Konsortium, IWK (Sewage)

Tenaga National Berhad, TNB (electric)

Gas Malaysia

The targeted users are submitting person / agent / developer / planning approver applicant of DBKL.

\subsection{Data and Study Area}

The data involve with DCP Malaysia is (but not limited to) within sample of DBKL boundaries:

- Land Use

- Cadastre

- Water

- Electricity

- Sewage Dataset

- Other GIS dataset

Optional data such road network, topo map (rivers, land covers, man-made features e.g. buldings are also included). Proposed drawing layout and as-built progress also could be used later in the proposed system.

Proposed study area is Kuala Lumpur Commercial Centre (KLCCC).

\section{THE PROPOSED GIS INTEGRATED SOLUTION}

In general implementation of GIS system/unit, there are three (3) main architectures:

$\begin{aligned} \text { i. } & \text { Stand-alone system } \\ \text { ii. } & \text { Enterprise System } \\ \text { iii. } & \text { Integrated GIS System }\end{aligned}$

A stand-alone system refers to any GIS Software that being installed in a machine (personal/organization computer/laptop). This architecture is based on individual activity without sharing data with colleagues, and clients in/outside the organization.

Some characteristics of stand-alone system are:

- Complex analysis can be done

- One staff need to update, delete data and produce info.

- Sharing data is not possible

- No involvement of database

- Severe security issue

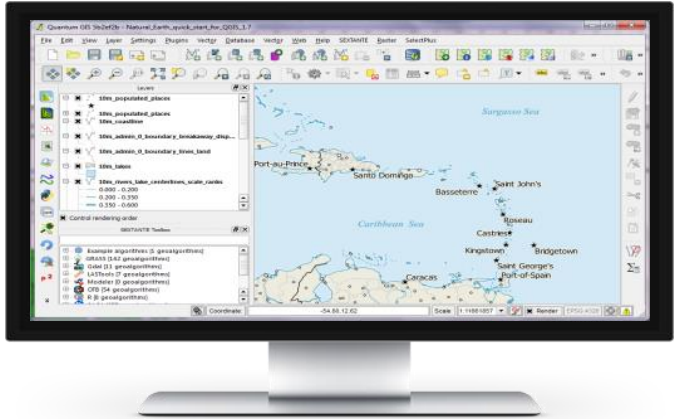

Figure 10: Illustration of a stand-alone system architecture.

An enterprise refers to a group GIS user/personnel working and sharing data/analysis/model among colleague within department/s and serves the whole organization. Any GIS Software will be installed in individual machine (personal computer/laptop) and GIS data/system will be shared among the group members. Some can share data view/information with client/public but not authorized to change the data.

Some characteristics of enterprise system are:

- Support more than one GIS online system for organization operation level / executive decision

- Complex analysis can be done using desktop software and upload it into the server

- Sharing data is possible among organization units in a local/cloud server.

- Live database (real-time update with good security level)

- Only working with organization data, no involvement with other's party dataset

- Decision only made by organization level. 


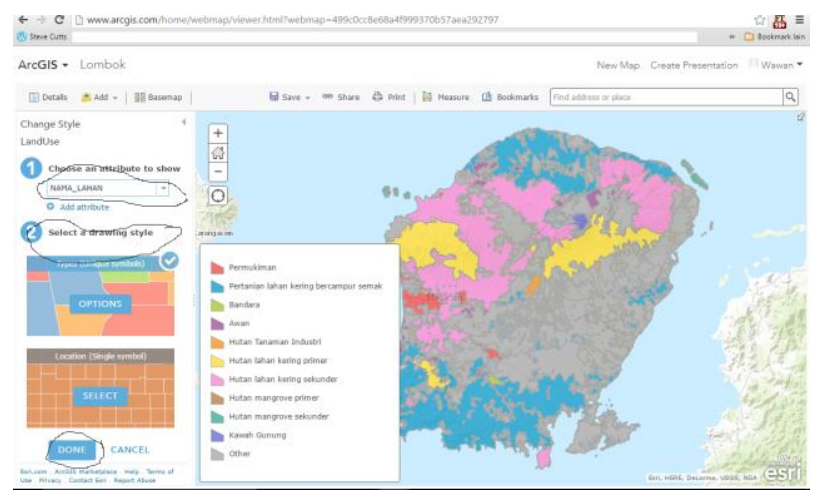

Figure 11: Example of an Enterprise GIS system for an organization

An integrated GIS system refers to groups GIS users from various organizations which can share and link their dataset/system together and create a pool of integrated user and information from various GIS datasets. They also can view and extract information from other organization dataset as the mutual agreement/common policies/aims of the organizations group (stakeholders). It is also known as a collaborative network in sharing GIS information.

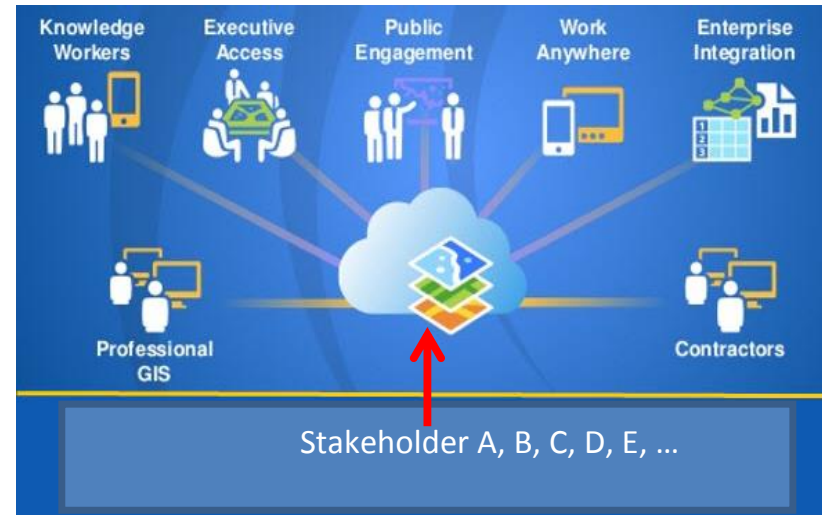

Figure 12: Illustration of an integrated GIS system architecture.

Some characteristics of integrated GIS system are:

- Support more than one GIS online system for organization operation level / executive decision

- Complex analysis can be done using desktop software and upload it into the server

- Sharing data becomes necessary among organization units in a local/cloud server.

- Live database (real-time update with good security level)

- Sharing/Editing data to stakeholders other than the designated pool is not possible.

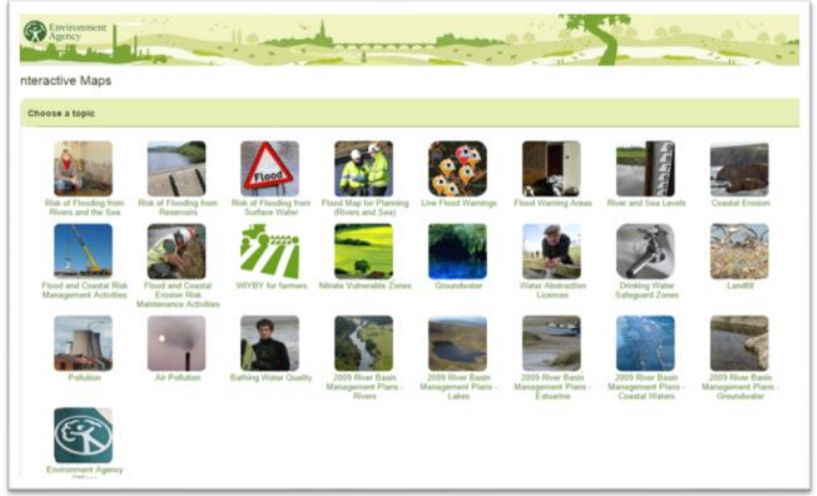

Figure 13: Another example of Integrated system, data/stakeholders/community contributing the spatial information.

\subsection{Proposed Architecture (Integrated/Collaborative Network)}

This solution enables not only the sharing of geospatial information within an organization but also within a common group/platform, as well as state/national level.

With the framework of technologies, policies, and institutional arrangements, together facilitate the creation, exchange, and use of geospatial data and related information resources across an information-sharing community. GeoMap allows data sharing within designated groups and only sharing within that social circle. This gains flexibility in data accessibility as well as enabling highly scalable system integration. Besides that, integrated GIS architecture enables environment that supports easy access to and utilization of geospatial data. SDIs are more than just data repositories:

- Discovery catalogues, search engine

- Visualization interactive maps, infographics, real time data, etc.

- Evaluation quality, metadata

- Access to geospatial data and information web-based, apps, services, GIS

Figure 14 and Figure 15 depicted scenarios where GIS can be collaborated through network via most frontier technology, such as Web API and related frameworks. Data security and accessibility can be both taken care working with a common platform. Vendor specific accessibility is also available in GeoMap. Figure 16 depicted a scenario where data sharing is only available in a closed group, such as a specific initiative or collaboration, GeoMap provides such flexibility and customizability to allow data provider share within only groups.

Besides, Figure 17 shows the typical system architecture that allows system integrators and different components to connect and collaborate through a common API standard. Figure 18 and Figure 19 show how the proposed Geomap publisher provides a solution for integration of different stakeholders dataset within a specific groups and managing the projects as per development request by applicants. Lastly, Figure 20 and Figure 21 show example of map viewer using vector and imagery dataset supported in the geomap publisher service (proposed solution for integrated DCP). 

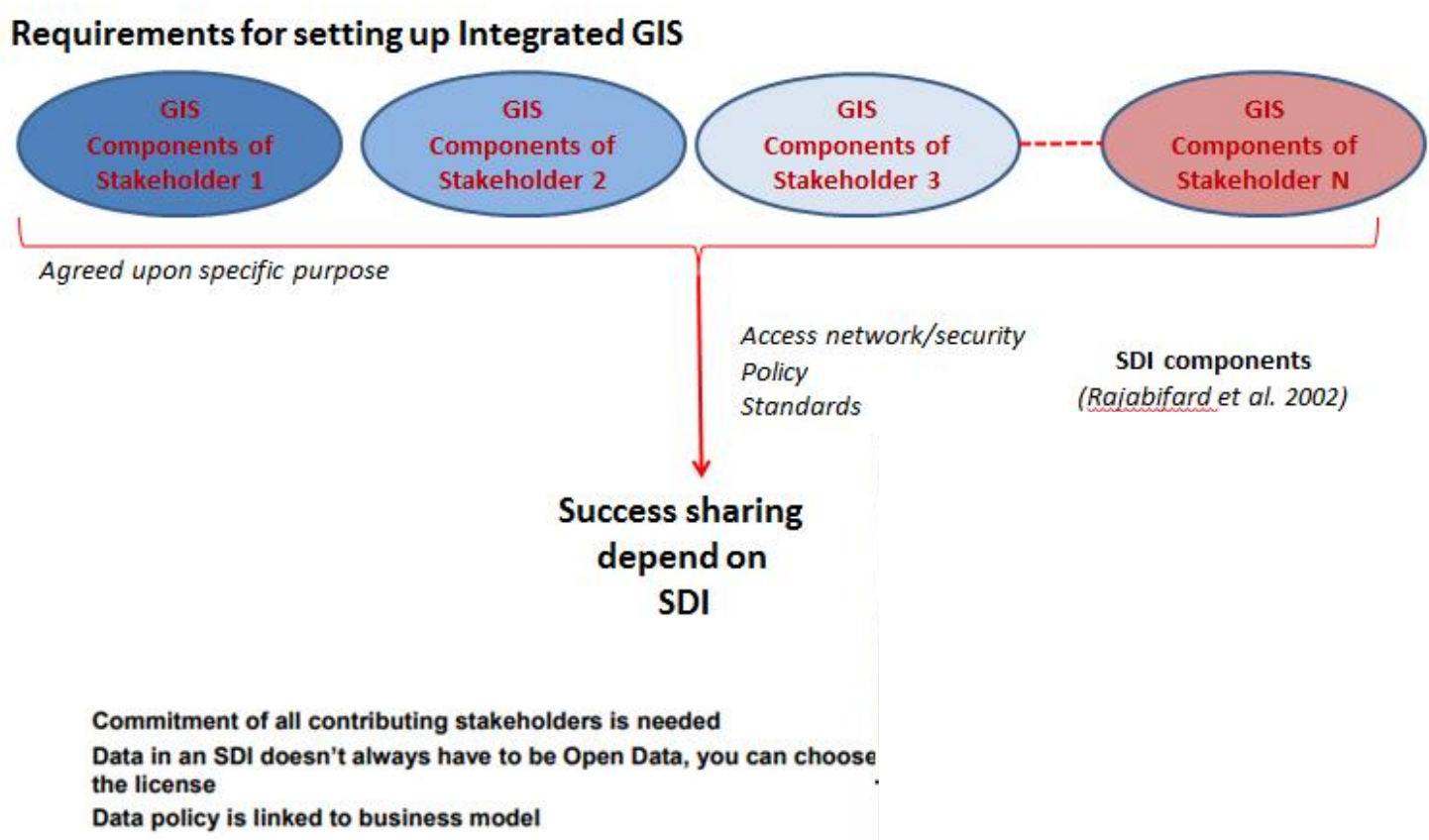

Figure 14: Requirement and flow for initiating integrated system with multiple stakeholders. (Rahabifard et al., 2002)

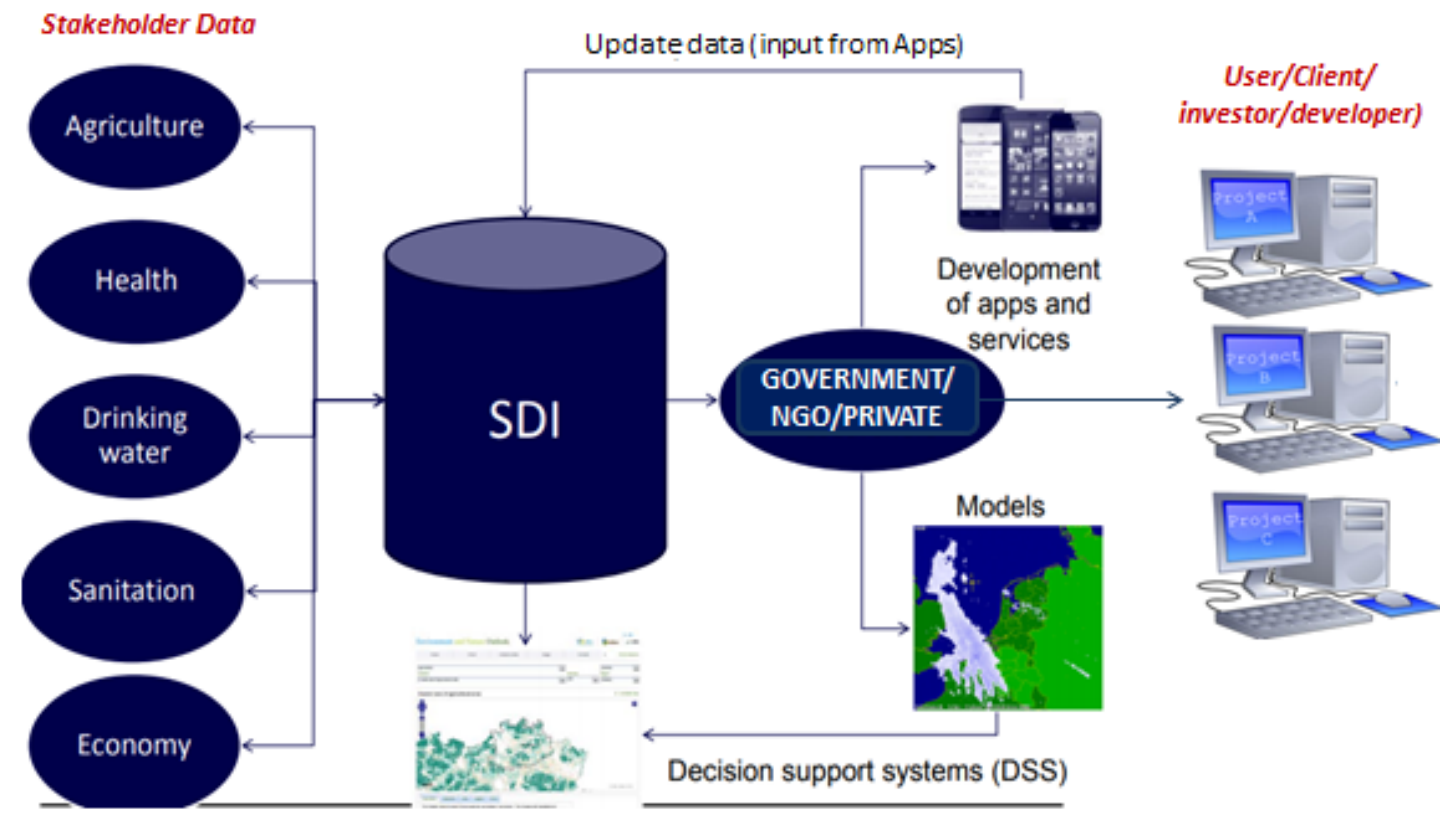

Figure 15: Example of a general integrated/collaborative architecture sharing design.

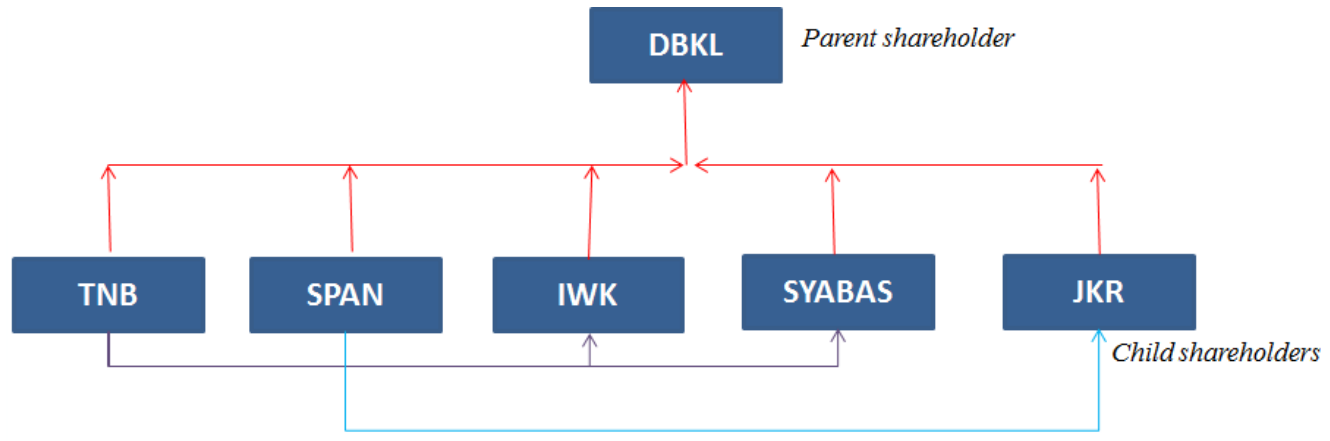

Figure 16: Example stakeholder hierarchy in sharing the aim/collaborative system in the proposed DBKL DCP group. 

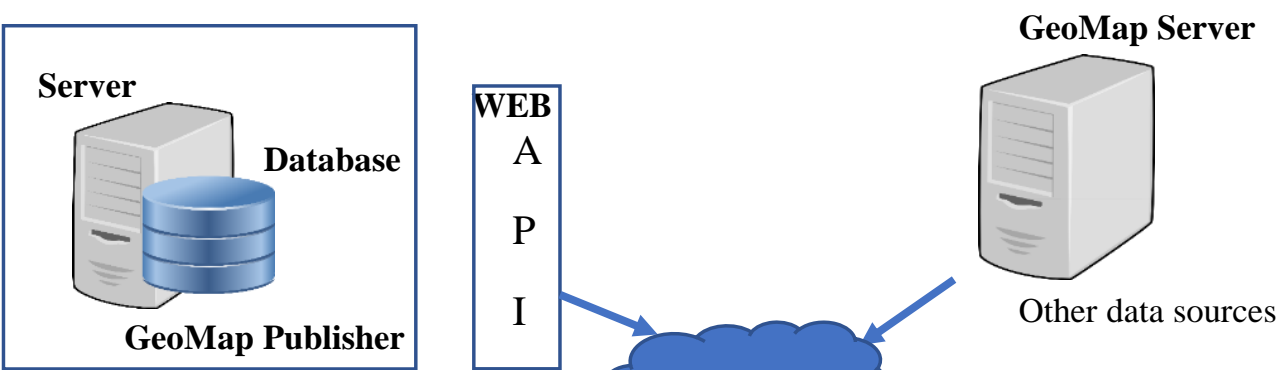

Figure 17: The typical GeoMap architecture over the web utilizing frontier API technology.

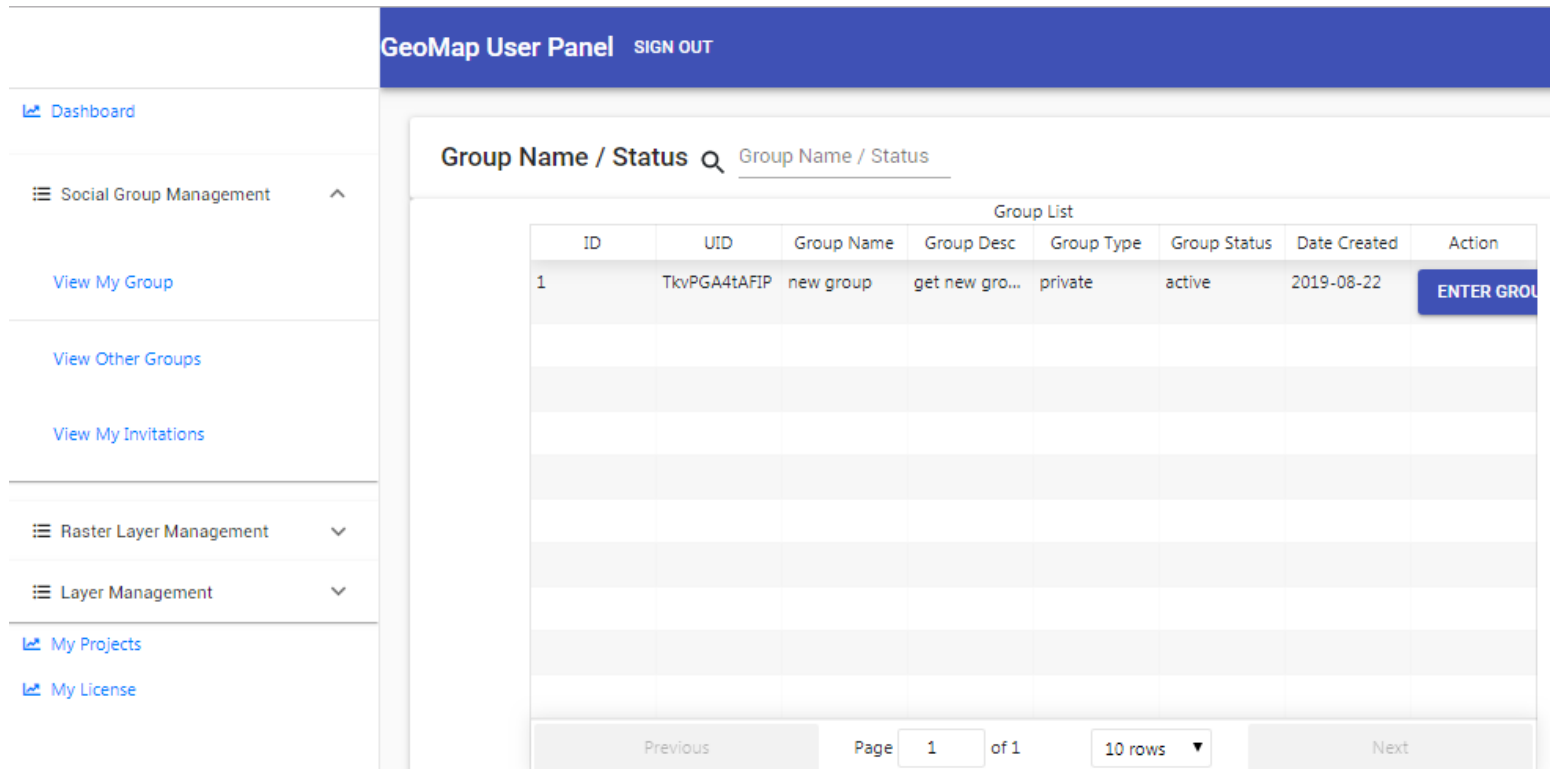

Figure 18: Example of joining a particular/private user group shared dataset from other group members (View My group-the account as Parent; View Other Group-the account as child/members - refers to Figure 16).

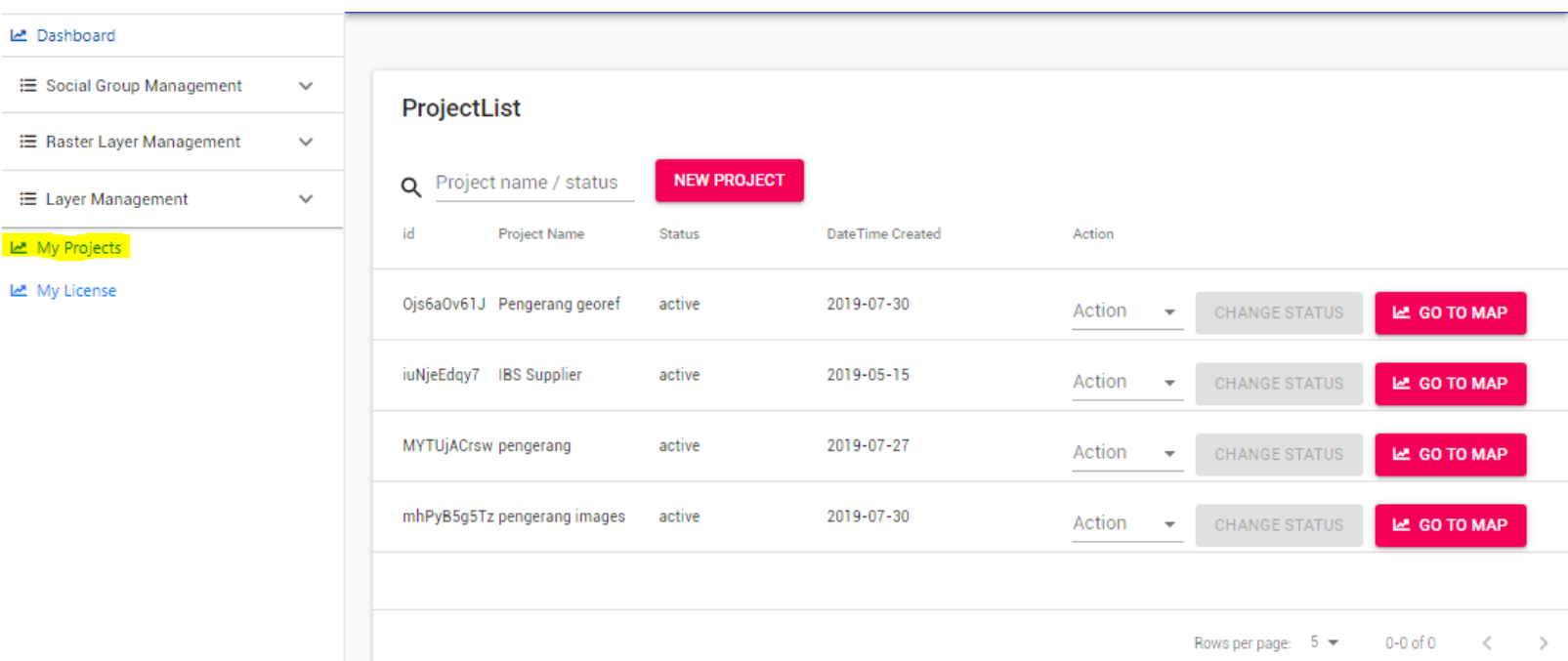

Figure 19: Proposed GIS integrated solution provides Project Management as for local authority and stakeholders to manage different location or development application from developers. 


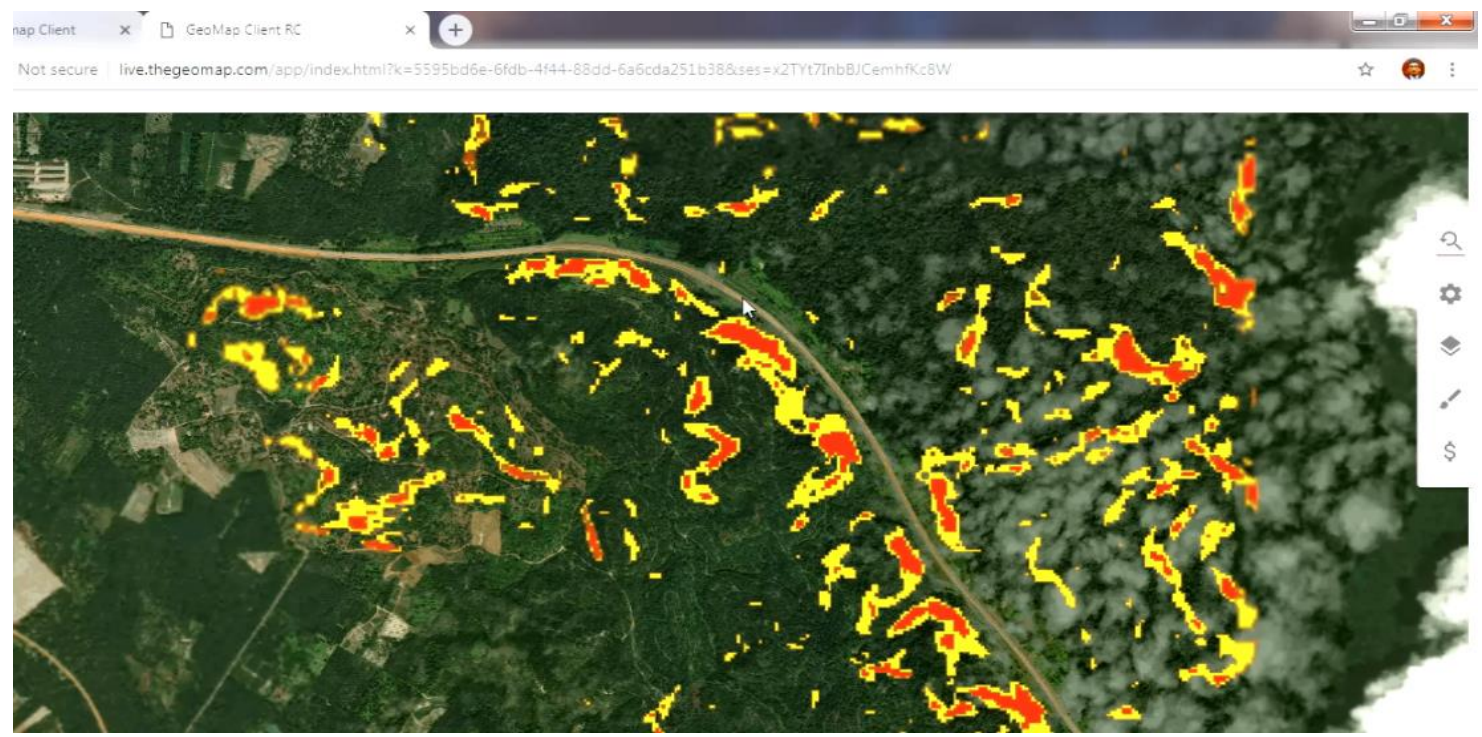

Figure 20: Example of GeoMap online viewer (vector dataset shared in a potential local authority DCP group) based on SDI concepts and enabling collaborative GIS architecture system (Figure 14 and 15).

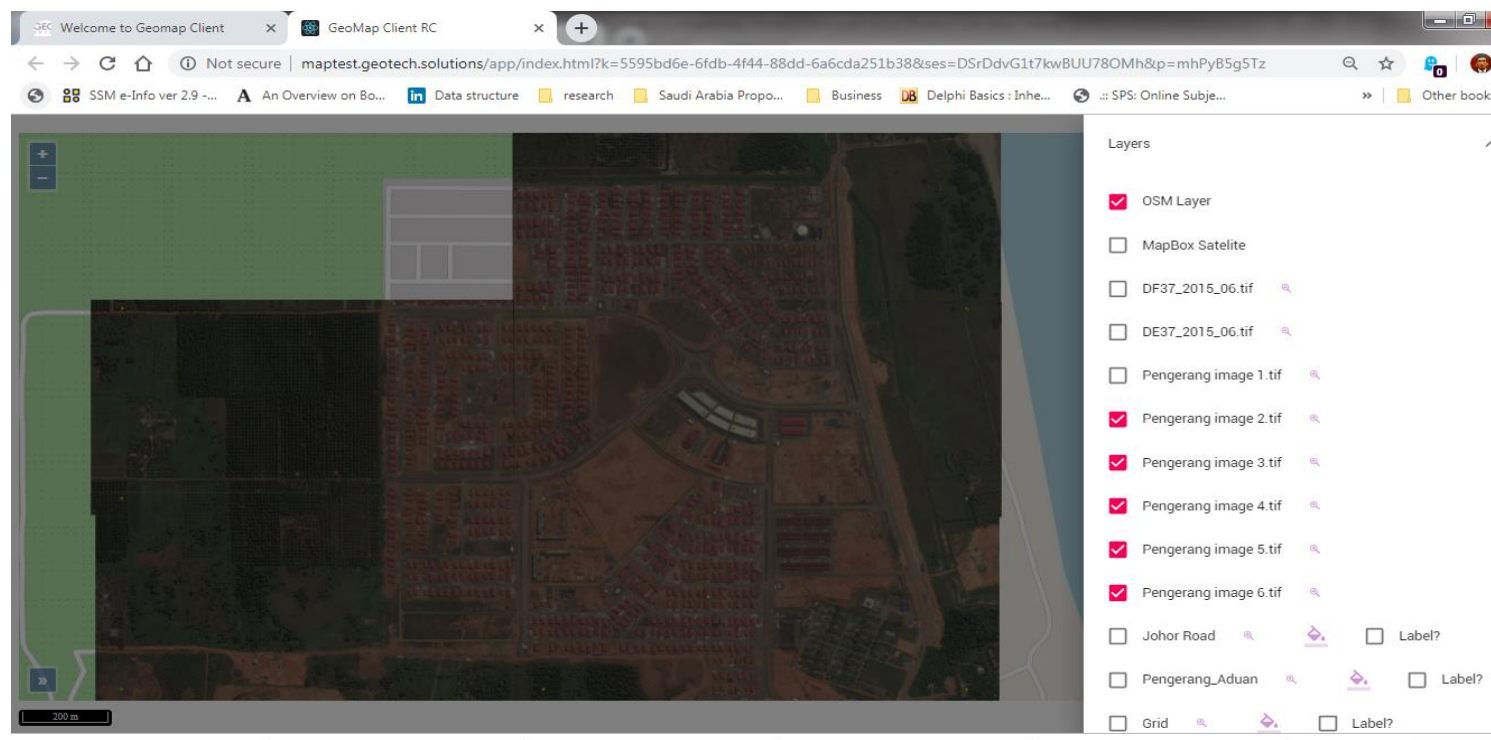

Figure 21: Example of GeoMap client viewer for shared imagery (e.g. from UAV drone) for other stakeholders and developer/applicant account.

The proposed solution (integrated solution, using Geomap service) will be discussed in details as the study progress of this initiative go further as well as for testing the dataset, security and functionality of the system. Some input from potential stakeholders and applicants will be discussed in the next publication.

\section{CONCLUSION}

The proposed concept/idea ultimately provides great benefits for local authority such as DBKL and other especially by simplifying the work, procedure and time taken for completing the requested development approval (kebenaran merancang $K M)$. This proposed solution directly will minimize the time taken for process 1 and process 2 (P1 and P2) in OSM v3.0 model. It will help a lot in acquiring and validating stakeholders GIS dataset (utility, infrastructure and topography) such as pipeline from SYABAS/IWK, cable and
PE of TNB (Tenaga National Berhad), proposed design from developer/applicant, road and drainage from JKR (Public Works Department) and JPS (Department of Irrigation and Drainage) and topographic dataset. By providing all necessary dataset from each involved stakeholders (security is well secured), there is no need to make appointment and site visit for each stakeholders with applicant and local authority personnel. Some cost also could be reduced since the time taken and mobilization are reduced greatly.

An impact study using this proposed solution is in progress when this paper is accepted. The proposed solution utilizes the available integrated GIS solution - GeoMap service (trial version). Involvement and suggestion from stakeholders will be acquired to assess the impact and related policies involving stakeholders, especially in dataset sharing. The result from this study determines whether we should engage or ignore the $5^{\text {th }}$ suggestion by World Bank Group, or to enhance with other initiatives. 


\section{REFERENCES}

B. Cantwell, J.F. Milem, 2010. International Encyclopedia of Education (Third Edition)

ESRI, 2007. A Framework for Understanding, Managing, and Improving Our World. In ArcNews Online 2007. https://www.esri.com/news/arcnews/fall07articles/gis-thegeographic-approach.html

Foziah Johar, Ahris Yaakup, Noordini Che'Man, Susilawati Sulaiman, and Mahadi Che Ngah., 2006. GIS in Development Control Process: The Case of Development Control System for City Hall of Kuala Lumpur. $6^{\text {th }}$ ASIAGIS Conference, Malaysia March 9-10,2006.

Manual Submission of Development Proposals Through the One Stop Center (OSC), City Hall Kuala Lumpur

Rajabifard, A., Feeney, M.-E.F. and I.P. Williamson (2002). Directions for the Future of SDI Development, International Journal of Applied Earth Observation and Geoinformation, 4(2002): 11-22

WBG, 2019. A World Bank Group Flagship Report, 16th Edition, 2019. Doing Business (Training for Reform).

Yaakup, A., F. Johar, and I.M. Yusof. Development Control System and GIS for Local Authority in Malaysia: A Case of Kuala Lumpur City Hall. In Design and Decision Support Systems in Architecture and Urban Planning. DDSS. Maastricht, The Netherlands: Eindhoven University of Technology, 1998. http://papers.cumincad.org/data/works/att/ddss9863.content.pdf 